\title{
Reliability and minimal detectable change of between-limb synchronization, weight-bearing symmetry, and amplitude of postural sway in individuals with stroke
}

\author{
Suzane Ketlyn Martello ${ }^{*}$, Tatiane Caroline Boumer ${ }^{1}$, Juliana Carla de Almeida ${ }^{1}$, Katren Pedroso Correa ${ }^{1}$, \\ Gisele Francine Devetak ${ }^{1}$, Rodrigo Faucz ${ }^{2}$, Elisangela Ferretti Manffra ${ }^{1}$ \\ ${ }^{1}$ Health Technology Graduation Program, Pontificia Universidade Católica do Paraná, Curitiba, PR, Brazil. \\ ${ }^{2}$ Gait Laboratory, Ana Carolina Moura Xavier Hospital Rehabilitation Center, Curitiba, PR, Brazil.
}

\begin{abstract}
Introduction: Recently, variables related to between-limb synchronization of the centers of pressure (COP) have been proposed as measures of postural control in post-stroke patients. Although it is crucial in verifying their potential clinical use, the reliability of these variables is unknown. The aim of this work was to determine the reliability and minimal detectable change (MDC) of the peak of synchronization $\left(\rho_{\max }\right)$ in the anteroposterior (AP) and mediolateral (ML) directions, the time lag for the peak $\left(\rho_{\max } \operatorname{lag}\right)$, synchronization at lag zero $\left(\rho_{0}\right)$, weight-bearing symmetry, and amplitude of postural sway, measured as the root mean square (RMS) values of the COP displacements in both directions (AP and ML COP displacement). Methods: COP data of 16 participants with stroke were collected at quiet standing with two force plates at two sessions separated by 2 to 7 days. The procedure was repeated three times in each session. The within and between sessions reliability was determined by the intraclass correlation coefficient (ICC), and the MDC was obtained from the ICC between sessions. Results: The variables $\rho_{\max }$ lag in the AP and ML directions, as well as $\rho_{0}$ in the AP direction, exhibited poor within session reliability (ICC $\leq 0.4$ ). The findings revealed excellent within and between sessions reliability (ICC $\geq 0.89$ ) for weight-bearing symmetry and the RMS displacement in the AP direction, with MDC values of 5\% and $2.07 \mathrm{~mm}$, respectively. The remaining variables exhibited moderate reliability. Conclusion: Weight-bearing symmetry and AP COP displacement can be considered reliable variables for use in clinical practice.
\end{abstract}

Keywords Reliability, Minimal detectable change, Synchronization, Center of pressure, Stroke, Posturography.

\section{Introduction}

Deficits in postural control following a stroke are responsible for an increased risk of falls (Mansfield et al., 2012), increased difficulty in performing daily activities (Bohannon and Leary, 1995), and decreased quality of life (Garland et al., 2007). They are also correlated with personal perceptions of inability following hospital discharge (Desrosiers et al., 2002). Thus, intervention protocols were developed to accelerate the recovery of

This is an Open Access article distributed under the terms of the Creative Commons Attribution License, which permits unrestricted use, distribution, and reproduction in any medium, provided the original work is properly cited.

How to cite this article: Martello SK, Boumer TC, Almeida JC, Correa KP, Devetak GF, Faucz R, Manffra EF. Reliability and minimal detectable change of between-limb synchronization, weight-bearing symmetry, and amplitude of postural sway in individuals with stroke. Res Biomed Eng. 2017; 33(2):113-120. DOI: 10.1590/2446-4740.06816.

*Corresponding author: Health Technology Graduation Program, Pontifícia Universidade Católica do Paraná - PUCPR, Imaculada Conceição, 1155, CEP 80215-901, Curitiba, PR, Brazil. E-mail: susiketlyn@hotmail.com

Received: 30 Ago 2016 / Accepted: 01 June 2017 balance control in patients (Freyler et al., 2014; An and Shaughnessy, 2011); the effectiveness of these protocols should be assessed via reliable and objective measures.

Conventional measures of the center of pressure (COP), such as speed and area and amplitude of sway, which are obtained via posturography using a single force plate, are used to quantify changes in postural control and analyze the effects of therapeutic interventions following a stroke (Freyler et al., 2014; De Haart et al., 2004). However, it is not possible to identify mechanisms related to unilateral deficits and compensations of a non-paretic lower limb (van Asseldonk et al., 2006) by using only one force plate. Therefore, posturographic methods implementing two force plates were proposed for post-stroke patients; these methods allow measurement of the contribution of each lower limb to postural control (Genthon et al., 2008; Mansfield et al., 2011). Genthon et al. (2008) analyzed the trajectories of the centers of pressure under each foot and concluded the following: 1) that a paretic limb acts more passively in the standing position, and 2) that, although the non-paretic limb plays a major role in balancing control, it cannot fully compensate for the 
deficits of the paretic limb, and as such also contributes to overall dynamic instability.

More recently, Mansfield et al. (2012) proposed three measures derived from the COP under each foot to help understand the mechanisms involved in postural control following a stroke: weight-bearing symmetry, between-limb synchronization, and the amplitude of postural sway as measured by the root mean square (RMS) of the COP excursion; the latter two are measured in the anteroposterior (AP) and mediolateral (ML) directions.

Extant research has indicated that hemiparetic subjects rely on the non-paretic lower limb to bear most of their body weight during quiet standing (De Haart et al., 2004; Genthon et al., 2008). The weight-bearing asymmetry appears as a strategy to compensate for the postural impairment of the paretic limb while standing. However, this compensatory strategy leads to disuse of the paretic limb with negative consequences. Thus, although this is not the main cause of postural instability, balance training for stroke patients always includes weight-shift exercises that require individuals to use both limbs (Genthon et al., 2008). Therefore, weight-bearing symmetry can be used as a clinical indicator to assess the effectiveness of this type of training.

Between-limb synchronization, i.e., the correlation between COP movements under each foot, provides insight into the lack of interlimb muscle coordination, and its role in overall instability. Mochizuki et al. (2005) observed that healthy individuals exhibit high and positive between-limb synchronization in the AP direction, and moderate and negative between-limb synchronization in the ML direction. A study by Mansfield et al. (2011) revealed that post-stroke subjects exhibited decreased between-limb synchronization, larger postural sway, and increased weight-bearing asymmetry as compared to healthy controls. This ability to differentiate healthy from post-stroke individuals led to the proposition of synchronization as a potentially useful posturographic measure to assess postural control of post-stroke patients while standing (Mansfield et al., 2011).

Other studies on synchronization are more relevant in the clinical context and find an association between this measure and the risk of falls (Mansfield et al., 2012) and limb spasticity (Singer et al., 2013). Mansfield et al. (2012) observed that stroke patients that fell exhibited lower levels of synchronization as compared to those who did not have a tendency to fall; a significant correlation between synchronization and the score according to the Berg Balance Scale was found. Singer et al. (2013) reported that patients exhibiting spasticity demonstrated decreased synchronization as compared to individuals without spasticity. Therefore, between-limb synchronization of COP trajectories is a plausible measure to assess therapeutic measures aimed at reducing the risk of falls and spasticity.
The RMS of the COP displacement is a traditional measure used to evaluate the amplitude of postural sway. Studies indicate that the behavior of this variable differs between healthy individuals and post-stroke individuals in several ways (Mansfield et al., 2011). For instance, the COP excursion under each foot is similar across healthy individuals, but it is significantly higher in the non-paretic foot as compared with that of the paretic foot. Additionally, individuals who have suffered a stroke exhibit similar amplitudes of COP excursions in the AP and ML directions with respect to the paretic foot, while the AP excursion under the non-paretic foot is higher than that in the ML direction. This difference between limbs is not present in healthy subjects. Furthermore, the ability to differentiate between healthy individuals and stroke patients is made apparent in the RMS COP displacement, which is a possible clinical indicator.

Despite their potential clinical applicability, to the best of the authors' knowledge, studies have not examined the reliability and minimal detectable change (MDC) of the synchronization and amplitude of postural sway in post-stroke patients. Gray et al. (2014) evaluated the within and between sessions reliability of the amplitude of postural sway of each foot as independent entities, and Eng and Chu (2002) and Gasq et al. (2014) examined the weight-bearing symmetry. However, these studies did not investigate the MDC of the aforementioned measures. The reliability of a measure refers to its stability under a set of sessions in which the same procedure is repeated using the same measurement system over a short period of time. Variables with high reliability present consistent values, which characterizes their suitability for clinical use. The MDC refers to the minimum magnitude of a change for it to be considered as significant (Haley and Fragala-Pinkham, 2006; Weir, 2005). Knowledge of these features is considered as a prerequisite for implementing a variable as an outcome measure to evaluate rehabilitation interventions and guide decision-making processes. It is not possible to apply a simple comparison of means to differentiate random effects from real changes, because they do not account for day-to-day random variability.

In this context, the aim of the current study was to determine the within and between sessions reliability, as well as the MDC of between-limb synchronization, weight-bearing symmetry, and RMS amplitude of postural sway.

\section{Methods}

The study was approved by the Ethics Committee of the Pontifícia Universidade Católica do Paraná $\left(\mathrm{n}^{\mathrm{o}} 256.523\right)$, and informed consent was obtained from all subjects. 


\section{Participants}

The study was conducted in the Gait Laboratory of the Centro Hospitalar de Reabilitação Ana Carolina Moura Xavier, which is a state rehabilitation hospital in Curitiba, Brazil.

Patients admitted to the physical therapy program were invited to participate in the study after their first evaluation session. A researcher was authorized to attend the sessions and personally invite the patients.

The following inclusion criteria were considered: 1) age $\geq 18$ years; 2) ability to stand for $60 \mathrm{~s}$ without the assistance of another individual, and 3) ability to understand the instructions for undergoing posturography. Patients with bilateral stroke or bilateral involvement, diplopia, uncorrectable reduced vision, and any other neurological or musculoskeletal disorders unrelated to stroke were excluded from the study.

The clinical evaluations undergone by the participants were as described next. The spasticity of the plantar flexors and degree of dependency on the ambulation were evaluated with a modified Ashworth scale (Bohannon and Smith, 1987), and by implementing the Functional Ambulation Category (FAC) (Mehtholz et al., 2007), respectively. The Berg Balance Scale was implemented to evaluate the balance (Miyamoto et al., 2004), and the Barthel Index was used to measure the degree of assistance required to perform daily living activities (Cincura et al., 2009). Additionally, ankle proprioception was tested in the paretic limb. The subjects were blindfolded and asked to answer questions related to the current joint position (flexion or extension). The performance was graded as normal (accurate and prompt answers), impaired (accurate but delayed answers), and absent (wrong answers). The subjects comprised 16 volunteers (seven women and nine men; 10 with right hemiparesis and six with left hemiparesis); characteristics of the participants are presented in Table 1.

\section{Procedures}

Static posturography measurements were obtained with two force plates (AMTI, OR6-7-1000), with the subjects standing as quietly as possible with each foot on a plate. The feet were positioned such that the axes from the heels to the toes were oriented at $14^{\circ}$, with the centers of the heels $17 \mathrm{~cm}$ apart (McIlroy and Maki, 1997). The participants were instructed to quietly remain in this position for a period of 60 seconds (Zok et al., 2008). This was performed thrice, with a resting interval of 2 min between repetitions, when the participants remained seated on a chair. Within an interval of 2 to 7 days following the test session, the procedures above were repeated under identical conditions with respect to the time of day, evaluators, and room temperature. The signals were sampled at $300 \mathrm{~Hz}$ and low-pass filtered using a fourth-order dual-pass $10 \mathrm{~Hz}$ Butterworth filter prior to processing.

\section{COP signal processing}

The initial $30 \mathrm{~s}$ of the collected signal were used to obtain the posturographic measures. The mean value was subtracted from the time series to eliminate offsets, and the cross-correlation of the COP time series between the left foot and right foot was calculated as an estimate of the synchronization of COP displacement between the feet. The synchronization was quantified by the following parameters (Mansfield et al., 2011; 2012): cross-correlation at time zero $\left(\rho_{0}\right)$, peak value of cross-correlation within $\pm 1 \mathrm{~s}$ from time zero $\left(\rho_{\max }\right)$, and the time-to-peak value from time zero $\left(\rho_{\max } \operatorname{lag}\right)$. All calculations were performed using the time series in the AP and ML directions. In addition to these synchronization measures, the amplitude of COP displacement was estimated from the RMS value of the corresponding time series. Weightbearing symmetry was calculated as the mean vertical force recorded by the force plate with lower weight bearing, and was expressed as a percentage of the total body weight (i.e., the total mean vertical force).

\section{Statistical analysis}

The Shapiro-Wilk test was applied to evaluate the normality of the distributions of $\rho_{\max }, \rho_{\max }$ lag, $\rho_{0}$, and RMS of COP displacement in the test and retest sessions. The test variable $\rho_{0}$ and retest variables $\rho_{0}$ and $\rho_{\max }$ in the AP and ML directions were compared with paired sample t-test, while the remaining variables were compared with Wilcoxon test. A significance level of $5 \%$ was considered in the study.

Table 1. Clinical characteristics of the participants $(n=16)$.

\begin{tabular}{lc}
\hline \multicolumn{1}{c}{ Variable } & Median \\
\cline { 2 - 2 } & (min-max) \\
\hline Age (yr). & $55(33-78)$ \\
Time post-stroke (mo.). & $6.5(1-20)$ \\
Weight (kg). & $67.8(57.9-88.8)$ \\
Height (m). & $1.63(1.50-1.77)$ \\
Body mass index (kg/m ${ }^{2}$ ). & $25.6(21.3-32.7)$ \\
Functional ambulation category (FAC). & $4(3-5)$ \\
Barthel index. & $83(65-100)$ \\
Berg balance scale. & $38(19-56)$ \\
Spasticity of the plantar flexors of the & $2(0-4)$ \\
paretic limb. & \\
Ankle proprioception of the non-paretic & $14 / 0 / 2$ \\
limb (normal / impaired / absent). & \\
Ankle proprioception of the paretic limb & $14 / 1 / 1$ \\
(normal / impaired / absent). & \\
Stroke etiology (hemorrhagic/ischemic). & $4 / 12$ \\
Hemiparetic side (left / right). & $5 / 11$ \\
\hline
\end{tabular}


The within session reliability was measured as the intraclass correlation coefficient (ICC two-way mixed) of the three same-day repetitions of posturographic measurements for both the test and retest sessions. To calculate between sessions reliability, the ICC from the averaged data of the three repetitions calculated for each session was used. To test the absence of systematic error, a single-factor (two-way) analysis of variance was applied. Prior to this analysis, the presence of homoscedasticity was assessed via the Levène's test. As a result, both conditions were found to be satisfied, which thus assured the correctness of the ICC values. The determination of the statistical model of the ICC followed the recommendations proposed in a study by Weir (2005).

MDC was determined based on Equation 1 (Weir, 2005):

$M D C=S E M * 2.13 * \sqrt{ } 2$

where SEM denotes standard measurement error, which is given as

$S E M=S D \sqrt{1-I C C}$

where the standard deviation (SD) is obtained from the total variance (Weir, 2005).

\section{Results}

Table 2 lists the median and minimum and maximum values of the variables determined in the same-day trials $\left(R_{1}, R_{2}\right.$, and $\left.R_{3}\right)$, and the average values of repeated measures. A comparison of results in the AP and ML directions revealed significant differences with respect to all variables except $\rho_{\max }$ lag.

Within session ICC values for $95 \%$ confidence obtained in the test and retest are listed in Table 3.

Table 4 presents the between sessions ICC and MDC values corresponding to each variable; these values were calculated with $95 \%$ confidence.

\section{Discussion}

The values corresponding to synchronization in the ML direction were significantly lower than those in the AP direction for synchronization at time zero $\left(M L \rho_{\mathrm{o}}\right)$ and peak synchronization $\left(\mathrm{ML} \rho_{\max }\right.$ ); lower synchronization values in the ML direction were also found by Mansfield et al. (2011; 2012). The study indicated that a relationship existed between the AP $\rho_{0}$ and an increased risk of falling; it also suggested that the $\mathrm{AP} / \mathrm{ML} \rho_{0}$ was a more meaningful measure than the ML $\rho_{0}$ (Mansfield et al., 2012). These results were expected because post-stroke patients have been known to exhibit a greater control over postural sway in the AP direction (Roerdink et al.,

Table 2. Median, minimum and maximum values of posturographic variables.

\begin{tabular}{|c|c|c|c|c|c|}
\hline \multirow{2}{*}{$\begin{array}{c}\text { Test/ } \\
\text { Retest }\end{array}$} & \multirow[b]{2}{*}{ Variable } & \multicolumn{4}{|c|}{ Median (minimum-maximum) } \\
\hline & & $\mathbf{R} 1$ & $\mathbf{R 2}$ & $\mathbf{R 3}$ & $\begin{array}{l}\text { Average of } \\
\text { Repetitions }\end{array}$ \\
\hline \multirow{9}{*}{ TEST } & $\mathrm{AP} \rho_{\max }$ & $0.77(-0.42-0.85)$ & $0.67(-0.18-0.88)$ & $0.64(-0.40-0.92)$ & $0.65(-0.03-0.85)$ \\
\hline & $\mathrm{AP} \rho_{\max } \operatorname{lag}(\mathrm{s})$ & $0.00(-0.48-1.00)$ & $0.00(-0.25-1.00)$ & $0.00(-0.18-0.50)$ & $0.00(-0.18-0.49)$ \\
\hline & $\operatorname{ML} \rho_{\max }$ & $-0.43(-0.92-0.36)$ & $-0.53(-0.87-0.25)$ & $-0.58(-0.90-0.46)$ & $-0.43(-0.81-0.35)$ \\
\hline & ML $\rho_{\max } \operatorname{lag}(s)$ & $0.01(-1.00-1.00)$ & $0.00(-1.00-1.00)$ & $0.01(-0.42-1.00)$ & $0.02(-0.31-1.00)$ \\
\hline & $\mathrm{AP} \rho_{0}$ & $0.74(0.00-0.85)$ & $0.67(0.15-0.88)$ & $0.64(-0.05-0.92)$ & $0.65(0.17-0.85)$ \\
\hline & $\operatorname{ML} \rho_{0}$ & $-0.43(-0.91-0.24)$ & $-0.53(-0.87-0.46)$ & $-0.58(-0.87-0.24)$ & $-0.49(-0.81-0.19)$ \\
\hline & Symmetry (\%) & $32.16(14.27-9.57)$ & $33.64(15.10-49.41)$ & $33.87(13.39-49.43)$ & $33.10(14.25-48.97)$ \\
\hline & AP COP displacement (mm) & $7.50(1.89-21.46)$ & $7.26(2.74-18.34)$ & $7.46(2.20-21.14)$ & $7.30(2.28-20.32)$ \\
\hline & ML COP displacement (mm) & $10.88(4.20-39.88)$ & $10.05(4.32-35.40)$ & $11.15(4.06-25.50)$ & $10.86(5.47-32.34)$ \\
\hline \multirow{9}{*}{ RETEST } & $\mathrm{AP} \rho_{\max }$ & $0.55(-0.48-0.87)$ & $0.58(-0.27-0.90)$ & $0.54(-0.31-0.89)$ & $0.51(-0.05-0.78)$ \\
\hline & $\mathrm{AP} \rho_{\max } \operatorname{lag}(\mathrm{s})$ & $-0.01(-0.23-1.00)$ & $-0.01(-1.00-1.00)$ & $-0.02(-1.00-0.03)$ & $-0.01(-0.46-0.35)$ \\
\hline & $\operatorname{ML} \rho_{\max }$ & $-0.34(-0.77-0.35)$ & $-0.49(-0.88-0.45)$ & $-0.34(-0.74-0.46)$ & $-0.29(-0.77-0.25)$ \\
\hline & $\operatorname{ML} \rho_{\max } \operatorname{lag}(\mathrm{s})$ & $0.00(-1.00-0.94)$ & $-0.01(-1.00-0.16)$ & $0.01(-1.00-1.00)$ & $-0.04(-0.66-0.52)$ \\
\hline & $\mathrm{AP} \rho_{0}$ & $0.55(-0.31-0.86)$ & $0.57(-0.02-0.90)$ & $0.52(0.15-0.89)$ & $0.51(0.15-0.78)$ \\
\hline & $M L \rho_{0}$ & $-0.34(-0.76-0.19)$ & $-0.47(-0.87-0.14)$ & $-0.40(-0.74-0.34)$ & $-0.35(-0.77-0.17)$ \\
\hline & Symmetry (\%) & $38.35(21.15-49.25)$ & $37.04(18.02-49.89)$ & $37.34(20.50-48.92)$ & $38.10(20.62-49.35)$ \\
\hline & AP COP displacement (mm) & $6.74(3.05-16.51)$ & $6.54(4.12-18.41)$ & $6.90(3.96-16.67)$ & $7.40(3.87-17.20)$ \\
\hline & ML COP displacement (mm) & $13.41(4.85-27.49)$ & $11.70(6.10-28.87)$ & $8.01(4.97-28.48)$ & $11.24(6.35-28.28)$ \\
\hline
\end{tabular}

AP: anteroposterior; ML: mediolateral; R: repetition; $\rho_{\text {max }}$ : peak value of cross-correlation; $\rho_{\max }$ lag: time lag for the peak value of cross-correlation; $\rho_{0}$ : cross-correlation at lag zero; R: repetition (1, 2, and 3); COP: center of pressure. 
Table 3. Within session ICCs for test and retest.

\begin{tabular}{|c|c|c|c|c|}
\hline \multirow[b]{2}{*}{ Variable } & \multicolumn{2}{|c|}{ Test } & \multicolumn{2}{|c|}{ Retest } \\
\hline & $\begin{array}{c}\text { ICC } \\
\text { within session }\end{array}$ & $95 \% \mathrm{CI}$ & $\begin{array}{c}\text { ICC } \\
\text { within session }\end{array}$ & $95 \% \mathrm{CI}$ \\
\hline $\mathrm{AP} \rho_{\max }$ & 0.57 & $0.27-0.80$ & 0.18 & $-0.11-0.53$ \\
\hline AP $\rho_{\max }$ lag & $-0.06^{*}$ & $-0.27-0.28$ & $-0.013 *$ & $-0.22-0.32$ \\
\hline ML $\rho_{\max }$ & 0.57 & $0.28-0.80$ & 0.20 & $-0.09-0.55$ \\
\hline ML $\rho_{\max }$ lag & 0.16 & $-0.12-0.52$ & 0.08 & $-0.16-0.43$ \\
\hline $\mathrm{AP} \rho_{0}$ & 0.32 & $0.02-0.64$ & 0.13 & $-0.14-0.49$ \\
\hline $\operatorname{ML} \rho_{0}$ & 0.59 & $0.30-0.81$ & 0.37 & $0.06-0.67$ \\
\hline Symmetry & 0.96 & $0.92-0.99$ & 0.95 & $0.88-0.98$ \\
\hline AP COP displacement & 0.89 & $0.77-0.96$ & 0.88 & $0.76-0.95$ \\
\hline ML COP displacement & 0.72 & $0.47-0.88$ & 0.60 & $0.31-0.82$ \\
\hline
\end{tabular}

AP: anteroposterior; ML: mediolateral; $\rho_{\max }$ : peak value of cross-correlation; $\rho_{\max }$ lag: time lag to peak value of cross-correlation; $\rho_{0}$ : cross-correlation at lag zero; COP: center of pressure. ${ }^{*}$ Negative values due to a negative average correlation among items.

Table 4. Between sessions ICC and MDC values.

\begin{tabular}{lcccl}
\hline \multicolumn{1}{c}{ Variable } & $\begin{array}{c}\text { ICC } \\
\text { between sessions }\end{array}$ & $\mathbf{9 5 \%}$ CI & SEM & MDC \\
\hline $\mathrm{AP} \rho_{\max }$ & 0.73 & $0.22-0.90$ & 0.15 & 0.47 \\
$\mathrm{AP} \rho_{\max }$ lag & 0.72 & $0.19-0.90$ & 0.72 & $2.16 \mathrm{~s}$ \\
$\mathrm{ML} \rho_{\max }$ & 0.55 & $-0.30-0.84$ & 0.23 & 0.69 \\
$\mathrm{ML} \rho_{\max }$ lag & 0.78 & $0.36-0.92$ & 1.17 & $3.52 \mathrm{~s}$ \\
$\mathrm{AP} \rho_{0}$ & 0.88 & $0.67-0.96$ & 0.07 & 0.21 \\
$\mathrm{ML} \rho_{0}$ & 0.70 & $0.14-0.90$ & 0.16 & 0.47 \\
Symmetry & 0.97 & $0.91-0.99$ & 1.66 & $5.00 \%$ \\
$\mathrm{AP} \mathrm{COP} \mathrm{displacement}$ & 0.97 & $0.92-0.99$ & 0.69 & $2.07 \mathrm{~mm}$ \\
ML COP displacement & 0.94 & $0.82-0.98$ & 1.60 & $4.81 \mathrm{~mm}$ \\
\hline $\mathrm{AP}$
\end{tabular}

AP: anteroposterior; ML: mediolateral; $\rho_{\max }$ : peak value of cross-correlation; $\rho_{\max }$ lag: time lag to peak value of cross-correlation; $\rho_{0}$ : cross-correlation at lag zero; RMS: root mean square; COP: center of pressure; ICC: intraclass correlation coefficient; CI: confidence interval; SEM: standard error of measurement; MDC: minimal detectable change.

2006). According to Roerdink et al. (2006), there is an overlap between the muscle activity of each of the lower limbs associated with COP displacement. While the ankle plantar flexors and dorsiflexors control the AP oscillations, the invertors and evertors contribute to both the AP and ML oscillations. The presence of spasticity in some of the muscle groups significantly influences the between-limb synchronization because the increased stiffness inhibits synchronization of the agonist and antagonist groups (Singer et al., 2013). In addition to the overlap between muscle actions, the measures may be moderately influenced by foot orientation (Rougier, 2008). Therefore, in this study, a standard foot position was adopted to limit variability among subjects.

Despite the lack of consensus with respect to which values of the ICC represent good or poor reliability (Weir, 2005), for the purposes of the analysis, ICC values smaller than 0.4 , between 0.4 and 0.75 , and larger than 0.75 were considered to represent poor, fair to good, and excellent reliability, respectively (Fleiss, 1999).

The variables related to lags (AP and ML $\mathrm{p}_{\max }$ lag) demonstrated high variability (Table 2), with the minimum and maximum values equal to -1 and +1 being observed in a few cases. These results indicate the need to increase the limits of the time lag. However, it is important to examine whether a lag higher than $1 \mathrm{~s}$ has a physiological meaning or corresponds to a random event. As expected, the lag variables were not reliable, as it can be ascertained from the within session ICC values shown in Table 3. Despite the higher values of the between sessions ICCs (Table 4), the $95 \%$ confidence interval resulted in negative values because of a negative average correlation among the items. These results indicate high variability among subjects and suggest that these variables are not suitable as practical indicators in clinical application.

Regarding the within session reliability, the weight-bearing symmetry yielded ICC values that exceeded 0.90 in both the test and retest, which was indicative of excellent reliability; additionally, AP COP displacement resulted in an ICC of 0.89 and 0.88 in the test and retest, respectively. The reliability of AP COP displacement exceeded the values indicated in a study by Carpenter et al. (2001), which aimed to evaluate the reliability by studying a sample population of 
healthy young adults by implementing trials of different durations. It was expected that lower ICC values would be observed in post-stroke subjects since they exhibit a higher variability inherent to deficits in postural control (Roerdink et al., 2006).

Similar to the findings of Gray et al. (2014), the values of within session reliability of the retest were lower as compared to those found in the test session. Possible causes could be related to the attention invested in the task and learning effects. Roerdink et al. (2006) analyzed the dynamic system measures of the data from the study by De Haart et al. (2004), which investigated the recovery of balance in post-stroke patients by using traditional posturographic measures. The analyses indicated that the COP displacement became less regular after an intervention. The authors attributed these results to a lower contribution of the cognitive component to the task, i.e., the maintenance of postural control while standing becomes more instinctive. In the current study, the patients could have invested more attention during the test, thereby resulting in a higher ICC than that determined from results of the retest. Therefore, an adaptation period is recommended prior to the real acquisition of data to avoid the task-learning effect.

None of the variables yielded poor between sessions reliability; this is likely because the average of the three trials was used in the calculation of between sessions reliability, thereby diminishing the effect of individual variability. Accordingly, Gray et al. (2014) showed that 2-3 trials are required to achieve stable average values of certain conventional COP measures for post-stroke subjects during a quiet stance. These results demonstrate the importance of determining the average of trials to obtain measures that are more reliable. However, better reliability was observed in the results from the first 2-3 trials, with decline observed in subsequent trials; this decline may be indicative of fatigue.

In addition to the number of trials, it is also interesting to analyze the trial duration, which is more appropriate to assess postural control after stroke while considering the variables under investigation. Ruhe et al. (2010) recommended an average of 3-5 trials, each with a minimum duration of $90 \mathrm{~s}$, to obtain consistent values of COP using conventional measures in healthy individuals. Doyle et al. (2007) only found acceptable levels of reliability after performing a minimum of five $60 \mathrm{~s}$ trials using the same sample population, suggesting that intra-subject variability tends to reduce when the length of trials is extended. Carpenter et al. (2001) observed an increase in ICC values of COP measures as the duration of the trial was increased from $15 \mathrm{~s}$ to $120 \mathrm{~s}$; as a result, it was suggested that a time series of $60 \mathrm{~s}$ should be employed to achieve stable measures in healthy young individuals. However, the study highlights the importance of considering the characteristics and limitations of the studied population by using higher sample duration. Gray et al. (2014) noted that, in the case of post-stroke subjects, the reliability of the measure could be compromised when the subject is exposed to long periods of standing. In the present study, despite collecting data for $60 \mathrm{~s}$, COP signal processing was only performed on the initial $30 \mathrm{~s}$ to ensure consistency with the methodology proposed by Mansfield et al. (2012), with which the measures under investigation were examined. Furthermore, a recent study found no difference between the reliability of COP displacement obtained from $30 \mathrm{~s}$ and $60 \mathrm{~s}$ time series (Martello et al., 2016). However, further research is still needed to evaluate the effects of time length on the reliability of the other variables.

The weight-bearing symmetry revealed excellent reliability, with $\mathrm{ICC}=0.97$, which is similar to the value reported by Eng and Chu (2002) for the same type of population; their study focused on determining the test-retest reliability of the weight-bearing of each limb during five standing tasks. One of the tasks required the subjects to remain in a quiet stance for $30 \mathrm{~s}$; data was collected from two trials. The weight-bearing of each limb of each subject was determined as a percentage relative to one-half of the body weight. Although the definition of symmetry used in the current study differs from that proposed by Eng and Chu (2002), a similar value of reliability was found here $(\mathrm{ICC}=0.95)$. This similarity was expected because the definitions of symmetry are linearly correlated. Gasq et al. (2014) also evaluated the reliability of this measure in the same population and observed poor reliability; however, they used only one force plate, and the weight-bearing symmetry was estimated from the mean COP position along the mediolateral axis. Therefore, it is difficult to compare the results. The variables of synchronization with respect to the sagittal plane yielded better between sessions reliability as compared to those for the frontal plane. These results confirmed the hypothesis of Mansfield et al. (2012) that suggested that the synchronization in the AP direction is a more significant measure than that in the ML direction, although it did not determine the reliability of the proposed variables. Additionally, it was concluded that, with respect to the AP direction, the synchronization at time zero ( $\mathrm{AP}_{0}$ ) was more reliable than the peak value ( $\left.\mathrm{AP}_{\max }\right)$.

Given the aforementioned results, it is possible to more thoroughly analyze the results of previous studies that used identical variables to evaluate clinical interventions. For instance, a study by De Haart et al. (2004) evaluated the effects of a rehabilitation intervention on the balance of post-stroke subjects by determining the AP and ML COP displacements. Following 12 weeks 
of individualized therapy, improved postural stability as evidenced by decreases in RMS values was observed. The results of the current study verify (with 95\% confidence) that the observed change is clinically relevant, i.e., the change is related to patient evolution and not merely due to random day-to-day variability.

A possible limitation of studies in post-stroke subjects is that the muscular spasticity is not stable since it is influenced by environmental factors. In an attempt to minimize a possible variation in muscle tone between sessions, the trials were always performed at approximately the same time of the day in a temperature-controlled environment. The relatively small sample size is another potential limitation of the study. However, the methodology of the reliability calculation was accordingly adjusted for each variable as recommended in the study by Weir (2005); this adjustment was performed with respect to the homogeneity of variances and absence of systematic error, adjusting the statistical analysis for each case.

In summary, the results of the present study indicate that weight-bearing symmetry and AP COP displacement showed excellent reliability. This suggests that these variables are possible candidates for use as outcome measures in assessments of post-stroke patients in clinical settings. Conversely, variables related to temporal lag are not recommended, as they were found to yield moderate to poor reliability.

\section{Acknowledgements}

This work received financial support from CAPES (PROSUP - 59/2014) and Fundação Araucária (016/2011-p.19076). Authors are grateful to the editor and reviewers for their valuable contribution to improve the quality of the manuscript.

\section{References}

An M, Shaughnessy M. The effects of exercise-based rehabilitation on balance and gait for stroke patients: a systematic review. The Journal of Neuroscience Nursing. 2011; 43(6):298-307. PMid:22089406. http://dx.doi.org/10.1097/ JNN.0b013e318234ea24.

Bohannon RW, Leary KM. Standing balance and function over the course of acute rehabilitation. Archives of Physical Medicine and Rehabilitation. 1995; 76(11):994-6. PMid:7487452. http:// dx.doi.org/10.1016/S0003-9993(95)81035-8.

Bohannon RW, Smith MB. Interrater reliability of a modified Ashworth scale of muscle spasticity. Physical Therapy. 1987; 67(2):206-7. PMid:3809245. http://dx.doi.org/10.1093/ $\mathrm{ptj} / 67.2 .206$.

Carpenter MG, Frank JS, Winter DA, Peysar GW. Sampling duration effects on center of pressure summary measures. Gait \& Posture. 2001; 13(1):35-40. PMid:11166552. http://dx.doi. org/10.1016/S0966-6362(00)00093-X.
Cincura C, Pontes-Neto OM, Neville IS, Mendes HF, Menezes DF, Mariano DC, Pereira IF, Teixeira LA, Jesus PA, Queiroz DC, Pereira DF, Pinto E, Leite JP, Lopes AA, Oliveira-Filho J. Validation of the National Institutes of Health Stroke Scale, modified Rankin Scale and Barthel Index in Brazil: the role of cultural adaptation and structured interviewing. Cerebrovascular Diseases (Basel, Switzerland). 2009; 27(2):11922. PMid:19039215. http://dx.doi.org/10.1159/000177918.

De Haart M, Geurts AC, Huidekoper SC, Fassoti L, van Limbeek J. Recovery of standing balance in postacute Stroke patients: a rehabilitation cohort study. Archives of Physical Medicine and Rehabilitation. 2004; 85(6):886-95. PMid:15179641. http:// dx.doi.org/10.1016/j.apmr.2003.05.012.

Desrosiers J, Noreau L, Rochette A, Bravo G, Boutin C. Predictors of handicap situations following post-stroke rehabilitation. Disability and Rehabilitation. 2002; 24(15):774-85. PMid:12437863. http://dx.doi.org/10.1080/09638280210125814.

Doyle RJ, Hsiao-Wecksler ET, Ragan BG, Rosengren KS. Generalizability of center of pressure measures of quiet standing. Gait \& Posture. 2007; 25(2):166-71. PMid:16624560. http:// dx.doi.org/10.1016/j.gaitpost.2006.03.004.

Eng JJ, Chu KS. Reliability and comparison of weight-bearing ability during standing tasks for individuals with chronic stroke. Archives of Physical Medicine and Rehabilitation. 2002; 83(8):1138-44. PMid:12161837. http://dx.doi.org/10.1053/ apmr.2002.33644.

Fleiss JL. Reliability of measurement. In: Fleiss JL. The design and analysis of clinical experiments. New York: John Wiley and Sons; 1999. p. 1-28.

Freyler K, Weltin E, Gollhofer A, Ritzmann R. Improved postural control in response to a 4-week balance training with partially unloaded body weight. Gait \& Posture. 2014; 40(2):291-6. PMid:24836698. http://dx.doi.org/10.1016/j. gaitpost.2014.04.186.

Garland SJ, Ivanova TD, Mochizuki G. Recovery of standing balance and health-related quality of life after mild or moderately severe stroke. Archives of Physical Medicine and Rehabilitation. 2007; 88(2):218-27. PMid:17270520. http:// dx.doi.org/10.1016/j.apmr.2006.11.023.

Gasq D, Labrunée M, Amarantini D, Dupui P, Montoya R, Marque P. Between-day reliability of center of pressure measures for balance assessment in hemiplegic stroke patients. Journal of Neuroengineering and Rehabilitation. 2014; 21(3):11-39. http://dx.doi.org/10.1186/1743-0003-11-39. PMid:24649845.

Genthon N, Rougier P, Gissot AS, Froger J, Pélissier J, Pérennou D. Contribution of each lower limb to upright standing in stroke patients. Stroke. 2008; 39(6):1793-9. PMid:18369174. http:// dx.doi.org/10.1161/STROKEAHA.107.497701.

Gray VL, Ivanova TD, Garland SJ. Reliability of center of pressure measures within and between sessions in individuals post-stroke and healthy controls. Gait \& Posture. 2014; 40(1):198-203. PMid:24768116. http://dx.doi.org/10.1016/j. gaitpost.2014.03.191.

Haley SM, Fragala-Pinkham MA. Interpreting change scores of tests and measures used in physical therapy. Physical Therapy. 2006; 86(5):735-43. PMid:16649896. 
Mansfield A, Danells CJ, Inness E, Mochizuki G, McIlroy WE. Between-limb synchronization for control of standing balance in individuals with stroke. Clinical Biomechanics (Bristol, Avon). 2011; 26(3):312-7. PMid:21055854. http:// dx.doi.org/10.1016/j.clinbiomech.2010.10.001.

Mansfield A, Mochizuki G, Inness EL, McIlroy WE. Clinical correlates of between-limb synchronization of standing balance control and falls during inpatient stroke rehabilitation. Neurorehabilitation and Neural Repair. 2012; 26(6):627-35. PMid:22275158. http://dx.doi.org/10.1177/1545968311429688.

Martello SK, Boumer TC, Manffra EF. Influência do tempo de coleta na reprodutibilidade da amplitude de oscilação postural de indivíduos pós AVE. In: Anais do XXV Congresso Brasileiro de Engenharia Biomédica - CBEB; 2016; Foz do Iguaçu, Brazil. Foz do Iguaçu: Sociedade Brasileira de Engenharia Biomédica; 2016. p. 892-5.

McIlroy WE, Maki BE. Preferred placement of the feet during quiet stance: development of a standardized foot placement for balance testing. Clinical Biomechanics (Bristol, Avon). 1997; 12(1):66-70. PMid:11415674. http://dx.doi.org/10.1016/ S0268-0033(96)00040-X.

Mehtholz J, Wagner K, Rutte K, Meißner D, Pohl M. Predictive validity and responsiveness of the functional ambulation category in hemiparetic patients after stroke. Archives of Physical Medicine and Rehabilitation. 2007; 88(10):1314-9. PMid:17908575. http://dx.doi.org/10.1016/j.apmr.2007.06.764.

Miyamoto ST, Lombardi I Jr, Berg KO, Ramos LR, Natour J. Brazilian version of the Berg balance scale. Brazilian Journal of Medical and Biological Research. 2004; 37(9):141121. PMid:15334208. http://dx.doi.org/10.1590/S0100879X2004000900017.

Mochizuki G, Ivanova TD, Garland SJ. Synchronization of motor units in human soleus muscle during standing postural tasks. Journal of Neurophysiology. 2005; 94(1):62-9. PMid:15744004. http://dx.doi.org/10.1152/jn.01322.2004.
Roerdink M, de Haart M, Daffertshofer A, Donker SF, Geurts AC, Beek PJ. Dynamical structure of center-of-pressure trajectories in patients recovering from stroke. Experimental Brain Research. 2006; 174(2):256-69. PMid:16685508. http:// dx.doi.org/10.1007/s00221-006-0441-7.

Rougier PR. How spreading the forefeet apart influences upright standing control. Motor Control. 2008; 12(4):36274. PMid:18955744. http://dx.doi.org/10.1123/mcj.12.4.362.

Ruhe A, Fejer R, Walker B. The test-retest reliability of center of pressure measures in bipedal static task conditions: a systematic review of the literature. Gait \& Posture. 2010; 32(4):436-45. PMid:20947353. http://dx.doi.org/10.1016/j. gaitpost.2010.09.012.

Singer JC, Mansfield A, Danells CJ, McIlroy WE, Mochizuki G. The effect of post-stroke lower-limb spasticity on the control of standing balance: inter-limb spatial and temporal synchronization of centers of pressure. Clinical Biomechanics (Bristol, Avon). 2013; 28(8):921-6. PMid:23938181. http:// dx.doi.org/10.1016/j.clinbiomech.2013.07.010.

van Asseldonk EHF, Buurke JH, Bloem BR, Renzenbrink GJ, Nene AV, van Der Helm FCT, van der Kooij H. Disentangling the contribution of the paretic and non-paretic ankle to balance control in stroke patients. Experimental Neurology. 2006; 201(2):441-51. PMid:16814283. http://dx.doi.org/10.1016/j. expneurol.2006.04.036.

Weir JP. Quantifying test-retest reliability using the intraclass correlation coefficient and the SEM. Journal of Strength and Conditioning Research. 2005; 19(1):231-40. http://dx.doi. org/10.1519/15184.1. PMid:15705040.

Zok M, Mazzà C, Cappozzo A. Should the instructions issued to the subject in traditional static posturography be standardised. Medical Engineering \& Physics. 2008; 30(7):913-6. PMid:18243033. http://dx.doi.org/10.1016/j. medengphy.2007.12.002. 